\title{
Behavioral Intervention to Support Smoking Cessation and Treating Insomnia in an Elderly Woman Living in a Nursing Home: A Case Study
}

\author{
Inez Kristanti ${ }^{\mathrm{a}}$ and Adhityawarman Menaldi ${ }^{\mathrm{b} *}$ \\ ${ }^{a}$ Clinical Adult Magister-Profession, Faculty of Psychology, Universitas Indonesia, Depok, \\ Indonesia; ${ }^{b}$ Clinical Psychology Department, Faculty of Psychology, Universitas Indonesia, \\ Depok, Indonesia.
}

*Corresponding Author:

Adhityawarman Menaldi

Clinical Psychology Department

Faculty of Psychology, Universitas Indonesia

J1. Lkr. Kampus Raya, Depok, Jawa Barat

Indonesia, 16424

Tel.: +62 217270004

Email: amrasmin@gmail.com 


\title{
Behavioral Intervention to Support Smoking Cessation and Treating Insomnia in an Elderly Woman Living in a Nursing Home: A Case Study
}

\begin{abstract}
Elderly people are vulnerable to health problems, yet some of them also experience difficulties adhering to a healthy lifestyle. Frequent smoking behavior is often found in the elderly population. Thus far, one of the most effective methods to help the elderly overcome the smoking habit is through a behavioral approach, especially when it is supported by motivational interviewing (MI). This case study reports on a two-week smoking cessation process as it was conducted on a single elderly subject who lives in a nursing home using the principles of behavior modification and MI. Considering that the client not only had a smoking problem but also insomnia, the same method was applied to increase the client's amount and quality of sleep. Another behavioral technique which was also used in treating her insomnia was a deep breathing technique. The two-week period of intensive intervention resulted in data showing that the intervention was successful in lowering her cigarette consumption and gradually increasing her amount of sleep. This case study shows that a simple treatment can be done in a systematic and measurable way, in a relatively short time, to promote a healthy lifestyle among the elderly in nursing homes.
\end{abstract}

Keywords: behavioral modification; deep breathing; insomnia; motivational interviewing; smoking cessation

\section{Introduction}

As people get older, the probability of their experiencing health problems increases (Ferrucci, Koh, Bandinelli, \& Guralnik, 2007). People in the late adulthood stage, which describes the age range of 60-70 years, have a greater risk of contracting diseases compared to people in the young adulthood stage (Santrock, 2011). Some chronic conditions commonly experienced by the elderly include arthritis, hypertension, hearing loss, heart conditions, chronic sinus problems, poor eyesight, impaired orthopedics, arteriosclerosis, urinary complaints, diabetes, and insomnia (Santrock, 2011; Thakur, Banerjee, \& Nikumb, 2013). Therefore, it is important for the elderly to maintain a healthy lifestyle to improve their life expectancies.

Even so, some elderly have difficulties in adhering to a healthy lifestyle. One especially unhealthy habit for the elderly is cigarette consumption (Kim et al., 2013; Lim et al., 2016). In 2013, the Indonesian Ministry of Health's Center of Data and Information (Pusat Data dan Informasi Kementrian Kesehatan RI) reported that more than $30 \%$ of the elderly population consumed an average of 13 cigarettes per day. Among the elderly group, the age group of 55-64 years showed the highest prevalence of cigarette consumption at $37.5 \%$. In fact, the elderly who have a smoking habit have a greater health risk than people in the younger age groups. One possible reason for this is that most elderly smokers have already smoked over a long duration of their life, so the health impacts are already accumulated. Health risks from smoking include chronic obstructive pulmonary disease, lung cancer, and coronary heart disease (CHD) (Burgel \& Clini, 2014).

Considering the negative effects of smoking, many studies focus on smoking cessation, particularly to see if smoking cessation remains effective for reducing the smoking behavior 
when it has already become a habit for an elderly person (Abdullah, Lam, Chan, Leung, Chi, Ho, et al., 2008; Kim et al., 2013). In general, it is found that smoking cessation can still be carried out successfully even in old age. Health benefits can also still be obtained by the elderly who try to stop or stop smoking. Research on elderly smokers in the United States found that the risk of CHD declined after they stopped smoking (Shields \& Wilkins, 2013). Tian et al. (2011) also found that the elderly who had quit smoking for a long period of time could expect a longer life expectancy and a longer active life expectancy. Moreover, smoking cessation is also proven to improve cognitive function in the elderly (Mons, Schöttker, Müller, Kliegel, \& Brenner, 2013).

There are several intervention approaches that have already been developed for smoking cessation. The result of a systematic review conducted by Thurgood, McNeill, Clark-Carter, and Brose (2016) in smokers who are also substance abusers showed that smoking cessation can be effectively performed using nicotine replacement therapy, behavioral support, cognitive behavioral therapy, or counseling. A comparison between studies by Ciccolo and Busch (2015) suggested that pharmacological interventions by using bupropion and vernicle can help smokers who try to quit because both substances can relieve the symptoms of nicotine withdrawal. However, this kind of pharmacological therapy is usually constrained by costs, access, compliance with medication protocol, and the experience of side effects. Therefore, Ciccolo and Busch (2015) found that smoking cessation can be more effective when it is supported by a behavioral approach. This suggests that behavioral intervention still plays a vital role in reducing smoking behavior. The following review will outline the two kinds of behavioral interventions that have already been found to be effective in helping smoking cessation: behavioral contracting (Bowers, Winett, \& Frederiksen, 1987; Perkins, Conklin, \& Levine, 2008) and motivational interviewing (MI; Ciccolo and Busch, 2015; Heckman, Egleston, \& Hofmann, 2010).

Behavior modification describes "...the field of psychology concerned with analyzing and modifying human behavior" (Miltenberger, 2012). Behavior modification has a number of basic principles. These include focusing on behavior, basing the plan on standard behavioral principles, paying attention to the things that happen in the current environment, using procedures precisely, consistent implementation in daily life, using measurement to evaluate behavior changes, not focusing on past events to explain the causes of the behavior, and not trying to find hypothetical excuses/explanations to explain the behavior.

Behavior modification can be done using various techniques, one of which is behavioral contracting. Behavioral contracting is a technique for conducting self-management to achieve behavior change (Miltenberger, 2012). A behavioral contract is a written document in which the individual (client) identifies targeted behavior and agrees to the consequences of his/her behavior within a specific time period. In a behavioral contract, sometimes there is an outside party who serves as the contract manager to check whether the behavior is done in accordance with the contract and to apply the behavior consequences to the individual if necessary. Perkins et al. (2008) found behavioral contracting to be a successful method which can effectively help the process of smoking cessation in individuals who have already made a commitment to do so.

Meanwhile, MI is a client-centered and directive method of enhancing an individual's intrinsic motivation to change behavior by exploring and overcoming ambivalence (Miller \& Rollnick, 2002). MI helps reduce the individual's resistance to behavior changes by creating a discrepancy between the individual's current behavior and the purpose or value he/she believes in. There are 
five principles that underpin this approach (Miller, 1983): (a) to identify the discrepancy between thoughts and behaviors; (b) to support the autonomy of clients; (c) to express empathy; (d) to acknowledge resistance as a normal feeling; and (e) to avoid confrontation. In MI, the therapist does not attempt to advise or direct the client toward certain behaviors, but to ask questions that can help the client to find his or her own motivation from within.

The review conducted by Ciccolo and Busch (2015) showed that MI is more effective than brief advice in aiding smoking cessation, and found an even greater effect when MI is done by a qualified counselor or primary care physician, in longer contact periods (over 20 minutes), and more frequently (more than 2 sessions). Other reviews conducted by Ciccolo and Busch (2015) also indicated that MI is more ideal for aiding smoking cessation in individuals who have low motivation to stop smoking.

This paper will report on the procedures and effectiveness of the application of behavioral contracting supported by MI for smoking cessation in an elderly woman who lives in a nursing home. This study is a single subject study because the researcher was specifically asked by the nursing home to do an intervention on this particular individual. The researcher perceived this as an opportunity to administer a planned and measurable behavior-based intervention program. Through this paper, it is expected that the implementation of the intervention program on one subject can be replicated for further research or intervention on a related topic.

Considering that the research participant not only had a cigarette smoking problem but also an excessive coffee drinking habit that naturally leads to insomnia, the same intervention method was also applied to reduce the subject's coffee drinking habit to increase her amount and quality of sleep. Studies have found a link between cigarette consumption and insomnia because nicotine is a stimulant, so it naturally lengthens sleep latency and decreases total sleep duration, particularly during deeper sleep stages (Fucito, Redeker, Ball, Toll, Ikomi, \& Carroll, 2013; Jaehne, Unbehaun, Feige, Lutz, Batra, \& Riemann, 2012). To address the subject's insomnia problem, the researcher added the 4-7-8 deep breathing behavioral technique by Andrew Weil (2011) to the intervention. In this technique, the client is trained to breathe slowly while inhaling for four counts, holding the breath for seven counts, and then exhaling slowly for eight counts. According to Weil (2011), this technique can relax the body and ease the burdens of the mind, and it has been proven to help people sleep. While no one technique has been found that addresses both smoking and insomnia at the same time, it makes sense to tackle them simultaneously in this case because the techniques used to help alleviate each problem do not interfere with each other.

Research problems:

1. Can intervention using behavioral contracting and MI help smoking cessation in an elderly woman living in a nursing home?

2. Can intervention using behavioral contracting and MI help reducing the coffee drinking habit for an elderly woman living in a nursing home?

3. Can a deep breathing technique help overcome the problem of insomnia in an elderly woman living in a nursing home? 


\section{Methods}

\section{Participant}

The participant in this study was an elderly woman in a nursing home. The nursing home specifically asked the researcher to provide an intervention to address the participant's problems, especially the cigarette consumption problem. Assessment on the participant was performed using a semi-structured interview to find out her life history and details of her current smoking behavior (including number of cigarettes smoked per day, onset, triggers, etc.) and insomnia (including detailed sleep patterns and hours of sleep, onset, triggers, etc.).

\section{Case introduction}

"Dena" is a 61 year-old Chinese-Indonesian divorced woman living in a public nursing home in Jakarta. She is the oldest of four siblings and has two daughters, but neither agreed to personally take care of her. She is currently in a relationship with a fellow resident, "Alan," whom she met at her previous nursing home.

\section{Presenting complaints}

Nursing home staff and other residents complained that Dena was a heavy smoker. She smoked approximately $8-10$ cigarettes a day. She refused to quit smoking because she felt like she needed cigarettes to alleviate the "sourness" in her mouth.

Aside from the nursing home staff and other residents' complaints, Dena personally reported that she had trouble sleeping. In the past week, she could only sleep for 0-2 hours. She said that she would not have been able to sleep at all if her boyfriend, Alan, had not called her. Dena's trouble sleeping might also be caused by her coffee drinking habit, but she was not aware of that possibility. She consumed 2 packets of instant coffee per day, which she constantly diluted with mineral water until they were completely tasteless. She consumed her coffee from morning until night time, up to as late as 11 p.m.

Dena's unhealthy lifestyle included several health problems. Her blood pressure was constantly high, measuring approximately 180/110. Her sedentary lifestyle probably also contributed to the primary cause of her obesity $(\mathrm{BMI}= \pm 33.3)$.

\section{History}

Dena is a widow with two daughters who are currently in their mid and late forties. Dena reported that she lived in an unhappy marriage with a physically abusive and jealous husband whom she decided to leave at the age of 24 . She reported having once lived with her daughters in their in-laws' houses. She was treated poorly by her son-in-law with occasional verbal abuse, and was given inappropriate living conditions. Her eldest daughter eventually suggested that she move to a nursing home.

She had been living in the nursing home since 2005 and had been transferred twice. The first transfer was due to her heavy smoking habit, which was found to be a disturbance by nursing home staff and residents, and the second one was due to her romance with a fellow resident,

\footnotetext{
${ }^{1}$ Participant's real name is not used to ensure confidentiality.
} 
Alan. She has been living at her current nursing home for two months. She sometimes makes knitted goods that are sold to nursing home visitors; for this occasional work, she is paid by the nursing home.

With regard to her smoking and coffee drinking habits, Dena reported that she started smoking and drinking coffee at the age of 21. She felt that smoking relieved her tension and "cleared her mind." Her smoking habit worsened at the age of 33 when she smoked up to 2-3 packs of cigarettes $(1$ pack $=16-20$ cigarettes $)$ per day. She had never received any treatments for smoking cessation.

\section{Assessment results}

Dena presented as moderately groomed; she wore casual dresses during the intake appointment and subsequent therapy sessions. Her speech tone and volume were normal, and her speech rate was slow. Her person, place, and time orientations were good. Dena exhibited normal thought processes and average intelligence. She showed minimal insight into her problems but engaged in sessions cooperatively and collaboratively. Her multiaxial diagnosis can be seen in Table 1.

Table 1

Multiaxial diagnosis for Dena

\begin{tabular}{lll}
\hline Axis I & 316 & Maladaptive Health Behaviors Affecting Hypertension and Obesity \\
Axis II & V71.09 & No Diagnosis \\
Axis III & 401.9 & $\begin{array}{l}\text { Hypertension, essential } \\
\text { Obesity }\end{array}$ \\
Axis IV & 278.00 & Problems with primary support group, problems related to the social environment \\
Axis V & Global Assessment of Functioning (GAF) $=61$ (at admission) \\
& GAF $=67$ (at discharge) \\
\hline
\end{tabular}

Note. Multiaxial diagnosis was made in accordance to Statistical Manual of Mental Disorders (Diagnostic and Statistical Manual of Mental Disorders; 4th ed., text rev.; DSM-IV-TR; American Psychiatric Association, 2000).

\section{Case conceptualization}

This section will present the conceptualization of Dena's case based on the guidance from Miltenberger (2012) to formulate or define the case that will be intervened using a selfmanagement technique, which is a behavioral contract. In Dena's case, there were two behavioral excesses: cigarette consumption and excessive coffee drinking.

Smoking has been a habit for Dena for approximately 37 years. This smoking behavior elicited immediate contingencies, included a relaxed feeling, decreased tension, and a decreased sour taste in Dena's mouth. However, smoking could actually cause delayed negative outcomes, which include various health problems such as lung cancer or heart disease. Currently, Dena has already shown signs of these health problems, such as hypertension and coughing, but these are outweighed by the more immediately rewarding contingencies without regard for the emergence of negative outcomes.

Dena's insomnia due to excessive coffee consumption had a similar mechanism as the smoking problem. Coffee consumption had become a habit for Dena and elicited immediate contingencies such as a relaxed feeling and pleasure in her taste buds. Although delayed negative outcomes from excessive coffee consumption happened much faster than with the cigarette consumption 
problem, Dena was not aware of a connection between her coffee drinking habit and insomnia. Moreover, excess coffee consumption also causes negative health effects such as hypertension, which Dena is currently experiencing.

The conceptualization of Dena's case is summarized in Table 2.

Table 2

Case conceptualization

\begin{tabular}{lll}
\multicolumn{1}{c}{ Behavioral excess } & \multicolumn{1}{c}{ Immediate contingency } & \multicolumn{1}{c}{ Delayed negative outcome } \\
\hline Smoking & $\begin{array}{l}\text { Relaxed feeling } \\
\text { Release of tension } \\
\text { Decrease of sour taste in Dena's mouth }\end{array}$ & $\begin{array}{l}\text { Health problems: } \\
\text { - Hypertension } \\
\end{array}$ \\
& $\begin{array}{l}\text { - Heart diseases } \\
\text { - Lung cancer }\end{array}$ \\
Coffee drinking & Relaxed feeling & Insomnia \\
& Pleasure in the taste buds & Hypertension \\
\hline
\end{tabular}

Note. This table refers to Miltenberger (2012)

\section{Research Design}

The design of this research was a pre-post single subject design that monitored changes that occurred in the participant before, during, and after a behavioral intervention. The number of cigarettes smoked and the total hours of sleep were measured and evaluated every day throughout the intervention, for a total of 12 days.

\section{Measures}

For this research, we did not use any psychological measurement. For each meeting, we recorded Dena's number of cigarettes consumed, the latest time of day that she drank coffee on the previous day, and her total number of sleeping hours on a piece of paper.

\section{Ethics}

Approval of this research was obtained from the Ethics Committee of the Faculty of Psychology, Universitas Indonesia. An informed consent was read, discussed, and signed by the first author and the participant.

\section{Procedure}

The intervention on Dena was conducted intensively in eight sessions over a span of 12 days. The time period of 12 days was chosen by taking previous research results by Ciccolo and Busch (2015) into account, as well as the fact that that effective MI required a longer contact duration (over 20 minutes) and a higher frequency (more than 2 sessions). Therefore, the 12-day time period was considered ideal for achieving the expected behavior changes and maintaining such changes over a longer time period.

The intervention consisted of three main components: (1) MI for supporting smoking cessation and reducing coffee consumption; (2) behavioral contracting for supporting smoking cessation and reducing coffee consumption; and (3) a deep breathing technique to overcome insomnia. Table 3 provides an overview of the intervention process undertaken with Dena. 
Table 3

Course of treatment

\begin{tabular}{ll}
\hline \multicolumn{1}{c}{ Session } & \multicolumn{1}{c}{ Brief description } \\
\hline Session 1 & $\begin{array}{l}\text { Introduction, initial interview conducted using principles of MI, including recognizing a change statement in a } \\
\text { statement that reflects DARN } \\
\text { Verbal psychoeducation about the health risks of smoking and the effect of coffee drinking on insomnia, introduction } \\
\text { of the deep breathing technique to overcome insomnia } \\
\text { Verbal psychoeducation (continued), eliciting change talk related to behavior of smoking and drinking coffee until late } \\
\text { at night, retraining the deep breathing technique }\end{array}$ \\
Session 3 & $\begin{array}{l}\text { Psychoeducation with infographic tools, eliciting change talk, introduction of the behavioral contracting method and } \\
\text { asking Dena to make her first contract }\end{array}$ \\
Session 4 & $\begin{array}{l}\text { Reviewing the contract made in the previous session and providing reinforcement in the form of verbal appreciation } \\
\text { Session } 5\end{array}$ \\
Session 6 & Reviewing the contract made in the previous session, managing ambivalence through exploring value and transitional \\
Session 7 & Reviewing all sessions that had already progressed and termination
\end{tabular}

\section{Motivational Interviewing (MI)}

MI was performed throughout Dena's intervention, starting in the initial interview and ending at termination. This was done to maintain Dena's motivation throughout, in hopes of it being maintained even after the intervention ended. The stages of Dena's MI were as follows:

- Initial interview

An initial interview was carried out using the principles of MI. The therapist, which was the first author, did anamnesis by recognizing whether Dena had already posited change statements. The identification of change statements was done by classifying the statements into four types of change statements formulated by Rosengren (2009): desire, ability, reasons, and need (DARN). At the beginning of the intervention, Dena had not conveyed a change statement that was supposed to be the beginning of her behavior change, apparently because she did not yet have the knowledge about the impact of smoking cigarettes and drinking excessive coffee. Therefore, the second stage was to provide psychoeducation about the health risks of smoking cigarettes and drinking excessive coffee.

- Psychoeducation

During the second and third sessions, psychoeducation was done verbally. The topic of this psychoeducation was the negative long-term effects of smoking on the elderly's health, as well as the influence of a coffee drinking habit on insomnia. Dena seemed to adequately understand what the therapist conveyed, but she had difficulty repeating the information that was presented, particularly the information on the long-term effects of smoking. The therapist assumed this was because Dena had a relatively low level of education and difficulty thinking in abstract terms. At the fourth session, the therapist brought two infographic tools to aid in the psychoeducation on smoking health risks. The first infographic contained written information about the long-term effects of smoking, including diseases that could arise from prolonged cigarette consumption, supported by figures that were easy to understand. The second infographic contained information about 
foods that could be used as substitutes for smoking, such as milk, mineral water, ginseng, chewing gum, carrots, and celery. The therapist asked Dena which of these foods she could obtain in the nursing home. After the psychoeducation was complete, the two infographics were pasted on the wall next to Dena's bed so that she could read them more often.

- Eliciting change talk

The therapist did an oral evaluation about the knowledge Dena had already acquired from the psychoeducation process. After Dena was able to convey the essential information about the health risks of smoking and drinking coffee, the therapist asked an evocative question intended to bring up her change statement (eliciting change talk).

- Managing ambivalence

After the psychoeducation, even though Dena was able to follow the therapist's direction to talk about the changes that she could make to stop her unhealthy behavior; this seemed insufficient to make her motivation prevail. Sometimes Dena complained or refused to make the changes to which she had committed. In these instances, the therapist used two techniques in MI: exploring values and transitional summary. For the first, the therapist brought up the thing that currently has the most important value in Dena's life, which is to live a long life together with her boyfriend, Alan. After understanding what Dena considered important, the therapist performed a transitional summary by acknowledging that changing the habit of smoking and drinking coffee was quite difficult for Dena. This was followed up with the observation that unfortunately, if changes are not made, it could reduce Dena's chances of living a long and healthy life with Alan. Afterwards, the therapist asked Dena the evocative question that could engender a change statement again, and Dena was able to follow the therapist's direction very well.

\section{Behavioral contracting}

After Dena was motivated to reduce smoking and change her coffee consumption pattern, behavioral contracting was done. Starting with the fourth meeting, at the end of each meeting, the therapist asked Dena to write her commitment for that day down on paper. The behavioral contract included:

- The number of cigarettes that she would consume that day and the day after;

- The latest time she would drink coffee (at 8 p.m.) after which she would not drink any coffee;

- The period of time within which the contract would be executed (day and date).

Dena kept the behavioral contract to review it together with the therapist at the next meeting. The therapist checked whether or not the targeted behaviors listed in the contract were successfully accomplished. If they were achieved, the therapist provided reinforcement in the form of verbal appreciation and gave encouragement about her success in slowly reducing her smoking and coffee consumption. If the targeted behaviors were not achieved, the therapist asked about what things became obstacles for Dena in implementing the targeted behavior.

\section{Deep breathing}

First, the therapist explained the purpose and benefits of deep breathing to Dena. After she was motivated to learn the technique, the therapist instructed her in the deep breathing exercise while she sat on her bed. After several initial attempts, the therapist noticed that Dena was having 
difficulty holding her breath in accordance with the recommended counts (4-7-8), so the therapist modified the instructions by asking her to inhale, hold, and exhale slowly. After Dena mastered the technique in a sitting position, the therapist asked her to lie down and practice breathing slowly by herself. The technique was taught twice, in the second and third sessions. Dena reported that she practiced the breathing technique every day and subjectively reported that this technique helped her to sleep.

\section{Termination}

The last phase of the intervention was the termination, which included a review of what Dena had learned and performed in the intervention. In general, Dena showed a positive attitude and satisfaction with the intervention. She felt that the intervention helped her to reduce her cigarette consumption and address her insomnia problem. Dena also reported being committed to reducing her cigarette consumption gradually so that in the end she will be able to quit smoking and live a longer and healthier life with her boyfriend, Alan.

\section{Data Analysis}

Data analysis was conducted by creating a comparison chart of the number of cigarettes and the total hours of the participant's sleep before, during, and after the intervention took place.

\section{Results}

During and after the intervention, Dena's cigarette consumption showed a gradual decline, indicating that intervention managed to help her with the smoking cessation process. Additionally, the number of hours Dena slept also showed a gradual increase, indicating that the behavioral intervention she made to change her coffee drinking pattern (to stop drinking coffee after 8 p.m.), together with the deep breathing technique, were effective in overcoming Dena's insomnia problem (Figure 1 and Figure 2).

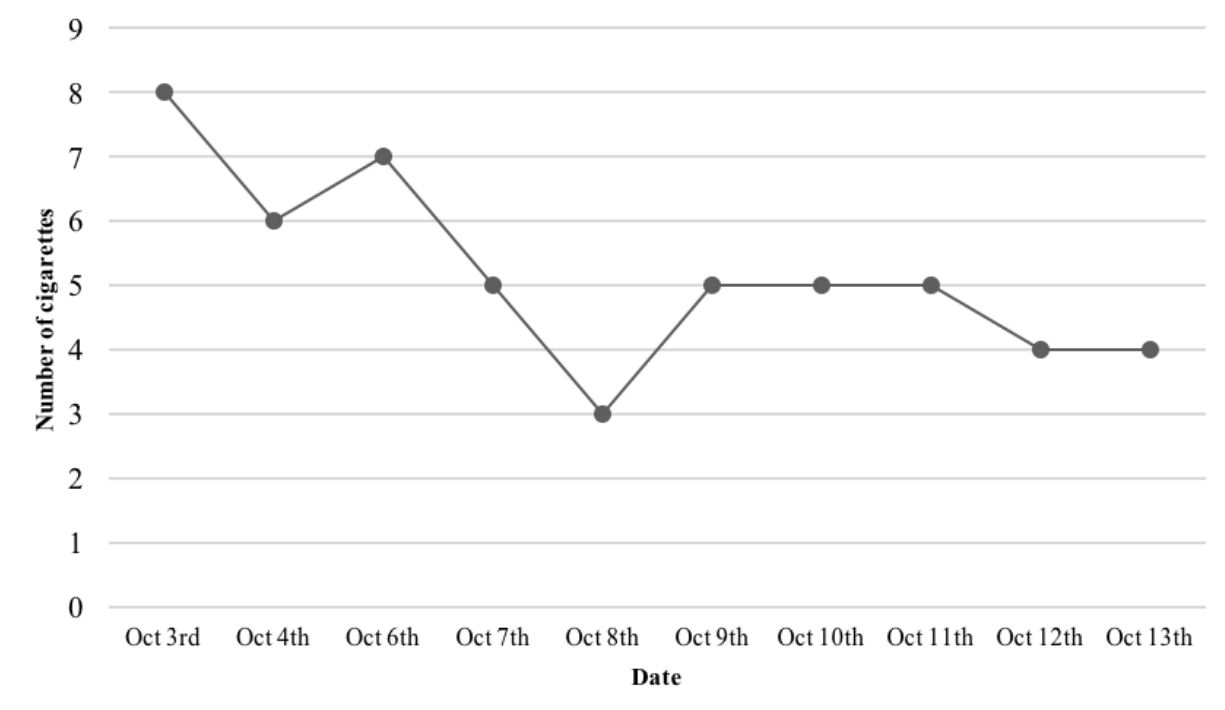

Figure 1. Changes in cigarette consumptions during the course of treatment 


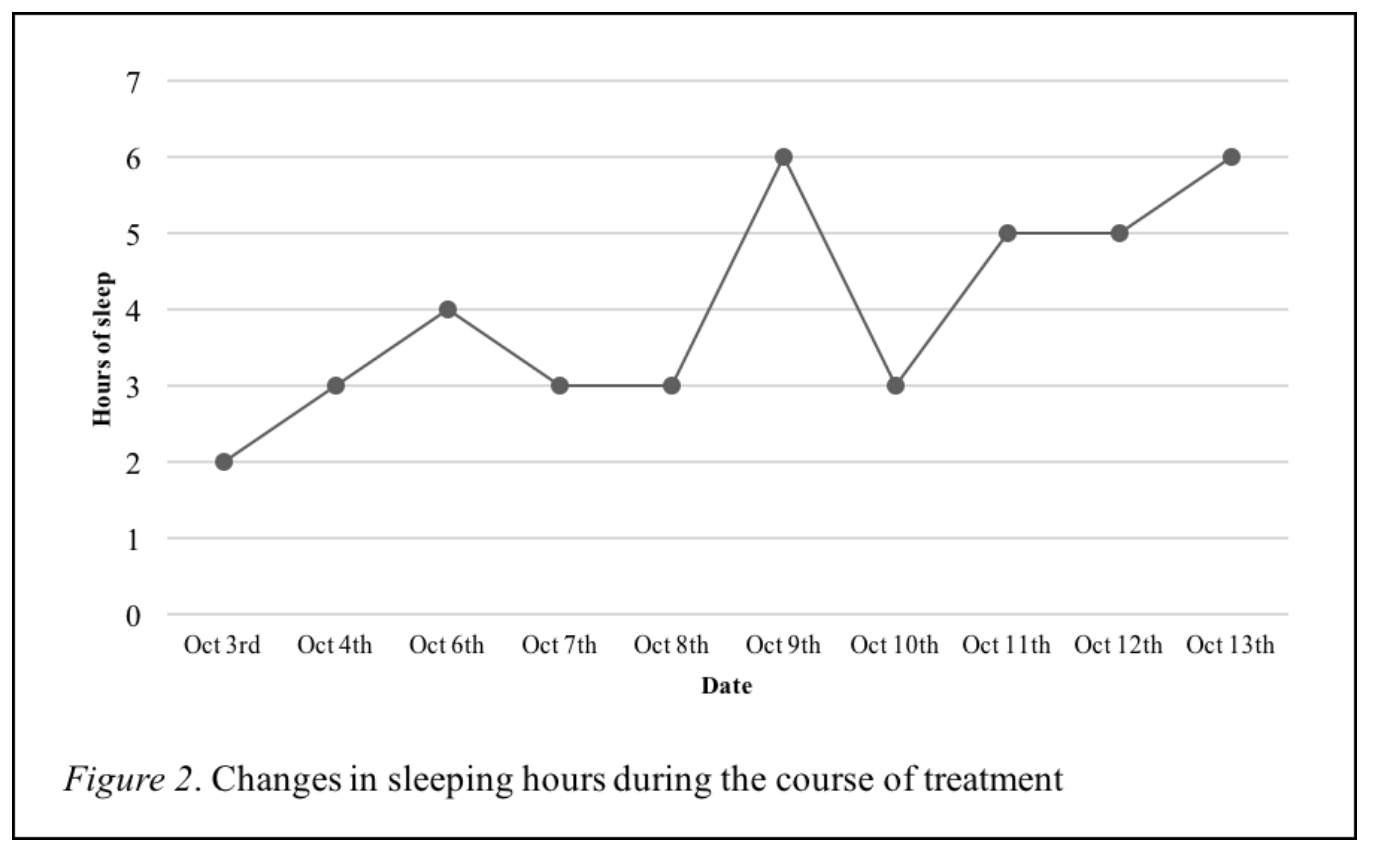

\section{Follow up}

A follow-up session was conducted two weeks after the termination occurred. The purpose of the follow-up session was to monitor whether Dena was able to maintain her progress without the therapist's assistance. In this session, Dena's knowledge about the health risks of smoking cigarettes and drinking excessive coffee, the estimated number of cigarettes and amount of coffee consumed per day, and the estimated number of sleeping hours were evaluated.

Dena reported that she had been consuming approximately 5 cigarettes per day. This was slightly more than her consumption at the time of termination, which was 4 cigarettes per day, but was nowhere near her initial cigarette consumption level, which had been 8-10 cigarettes per day. We noticed that Dena showed a lack of motivation around continuing the smoking cessation process. She reported that she was not sure that she could eventually stop smoking by reducing her cigarette consumption. The therapist needed to re-apply the techniques for managing ambivalence in MI, which consisted of exploring values and transitional summary. At the end of the session, Dena managed to regain her commitment to gradually reduce her smoking behavior. It is also important to note that Dena was still able to recite the contents of psychoeducation about the health risks of smoking given to her at the beginning of the intervention. She was also able to convey that her smoking behavior was not consistent with her value, which was to live a long and happy life with Alan.

With regard to her insomnia, Dena reported that in the past two weeks, her sleeping hours varied between approximately 2-5 hours per night, but she was able to sleep during the day, something that she was not able to do before taking part in this intervention. She reported that her lack of sleep at night was compensated by the amount of sleep she got during the day. She also reported that she had been continuing to practice the deep breathing technique to help her sleep. This indicated that Dena was still able to apply the knowledge she gained throughout the intervention to maintain her increased number of sleeping hours. 


\section{Discussion}

In general, the results show that an intervention conducted intensively by using the approaches of behavioral contracting, MI, and deep breathing can help smoking cessation and address the problem of insomnia in an elderly person in a nursing home. The score fluctuation during the intervention was caused by Dena's declining motivation to change her behavior, for which the therapist needed to re-apply the MI principles. After her motivation was stabilized, she was able to maintain the positive results with regard to lower cigarette consumption and more hours of sleep until two weeks later when the therapist did the follow-up session. This shows that the intervention was effective in creating a longer term change in Dena.

In addition to explaining the positive things achieved by this research, this section will also discuss things that might have obstructed this intervention, including limitations, implications of this case for the clinical intervention field, potential areas for next research, and recommendations for therapists. One of the things that hindered the intervention process was Dena's lack of insight into her problem and lack of motivation to make the changes to which had committed. The therapist had to perform several managing ambivalence techniques proposed in Rosengren (2009) in order to increase Dena's motivation. In the end, these efforts proved successful in leading Dena toward positive changes. One external factor that might have obstructed this intervention process was the involvement of other students who were also practicing in the nursing home where Dena stayed. Sometimes these students made negative comments about Dena's progress in reducing her cigarette consumption. They often teased Dena and doubted that her smoking habit could be reduced. In the process of behavioral modification, these comments could be considered some kind of punishment (Miltenberger, 2012) that could potentially weaken a subject's motivation to continue the treatment. From a methodological perspective, another limitation that might prevent researchers from drawing a strong conclusion from this study is that this study only utilized a single baseline and a single measurement. For future research, we strongly recommend the utilization of multiple baselines and multiple measurements in evaluating a client's progress.

Regardless of these barriers, this case study indicates that behavioral treatments still play an essential role in smoking cessation and overcoming insomnia. This result is in accordance with Ciccolo and Busch's (2015) finding that a behavioral approach is also needed to achieve satisfying results in a smoking cessation program. This case study also implies that for the elderly, the use of psychological techniques needs to be adapted to the client's individual physical, cognitive, and emotional conditions, which tends to be quite different in an elderly population. For example, the application of deep breathing in this case was deemed effective even though during the process, adjustments had to be made to the instructions so that the client was able to follow them. The behavioral approaches used in the intervention process were chosen with consideration for keeping the techniques simple and not involving complicated cognitive processes so that they could be well-received by an elderly person.

This case study shows that simple treatments can be performed in a relatively short time to promote healthy lifestyles for the elderly in nursing homes. Considering that many students from various majors (one of which is psychology) usually do their internships in nursing homes, the researcher recommends that simple interventions of this kind be done more often, and be implemented in a systematic and measurable way. In addition, the success of this intervention to 
change smoking behavior in the elderly population also opened up opportunities for other studies to implement behavioral modification and motivational interviewing in promoting other healthy behaviors, such maintaining a suitable diet for people with diabetes or other chronic diseases, doing exercise, or encouraging hygienic behavior. In addition, the methods used in this case study could also be replicated on a larger scale by using a larger sample, a comparison group, and stricter control on external variables to make sure the causal relationships and contributions given by the intervention can be clearly seen.

\section{References}

Abdullah, A. S., Lam, T. H., Chan, S. K., Leung, G. M., Chi, I., Ho, W. W., \& Chan, S. (2008). Effectiveness of a mobile smoking cessation service in reaching elderly smokers and predictors of quitting. BMC Geriatrics, 8, 25.

American Psychiatric Association. (2000). Diagnostic and statistical manual of mental disorders (4 ${ }^{\text {th }}$ ed., text rev.). Washington, DC: Author.

Bowers, T. G., Winett, R. A., \& Frederiksen, L. W. (1987). Nicotine fading, behavioral contracting, and extended treatment: Effects on smoking cessation, Addictive Behaviors, 12, 181-184.

Burgel, P. \& Clini, E. M. (2014). Multimorbidity in elderly patients with chronic obstructive pulmonary disease: Stop smoking! Go exercise? American Journal of Respiratory and Critical Care Medicine, 189(1), 7-8.

Ciccolo, J. T. \& Busch, A. M. (2015). Behavioral interventions to enhance smoking cessation: Summary of the current evidence. American Journal of Lifestyle Medicine, 9(2), 92-104.

Ferrucci, L., Koh, C., Bandinelli, S., \& Guralnik, J. M. (2007). Disability, functional status and activities of daily living. In J. E. Birren (Ed.), The encyclopedia of gerontology, $2^{\text {nd }}$ ed. (pp. 427-436). Oxford: Academic Press.

Fucito, L. M., Redeker, N. S., Ball, S. A., Toll, B. A., Ikomi, J. T. \& Carroll, K. M. (2013). Integrating a behavioural sleep intervention into smoking cessation treatment for smokers with insomnia: A randomised pilot study. Journal of Smoking Cessation, 9(1), 31-38.

Heckman, C. J., Egleston, B. L., \& Hofmann, M. T. (2010). Efficacy of motivational interviewing for smoking cessation: a systematic review and meta- analysis. Tobacco Control, 19(5), 410-416.

Jaehne, A., Unbehaun, T., Feige, B., Lutz, U. C., Batra, A., \& Riemann, D. (2012). How smoking affects sleep: a polysomnographical analysis. Sleep Medicine, 13(10), 1286-1292.

Kim, S. K., Park, J. H., Lee, J. J., Lee, S. B., Kim, T. H., Han, J. W., . . Kim, K. W. (2013) Smoking in elderly Koreans: prevalence and factors associated with smoking cessation. Archives of Gerontology and Geriatrics, 56, 214-219.

Lim, K. H., Jasvindar, K., Cheong, S. M., Ho, B. K., Lim, H. L., Lau, K. J., . . Ambigga, D. (2016). Prevalence of smoking and its associated factors with smoking among elderly smokers in Malaysia: findings from a nationwide population-based study. Tobacco Induced Diseases, 14(8), 1-8.

Miller, W. R. (1983). Motivational interviewing with problem drinkers. Behavioral Psychotherapy, 11, 147-172.

Miller, W. R. \& Rollnick, S. (2002). Motivational interviewing: Preparing people for change (2 ${ }^{\text {nd }}$ ed.). New York, NY: The Guilford Press.

Miltenberger, R. G. (2012). Behavior modification ( $5^{\text {th }}$ ed.). Belmont, CA: Wadsworth.

Mons, U., Schöttker, B., Müller, H., Kliegel, M., \& Brenner, H. (2013). History of lifetime smoking, smoking cessation and cognitive function in the elderly population. European Journal of Epidemiology, 28(10), 823-831.

Perkins, K. A., Conklin, C. A., \& Levine, M. D. (2008). Cognitive-behavioral therapy for smoking cessation: A practical guidebook to the most effective treatments. New York, NY: Taylor \& Francis.

Pusat Data dan Informasi Kementrian Kesehatan RI (2013, September). Gambaran Kesehatan Lanjut Usia di Indonesia. Jakarta: Kementrian Kesehatan RI.

Rosengren, D. B. (2009). Building motivational interviewing skills: A practitioner workbook. New York, NY: The Guilford Press.

Santrock. J. W. (2011). Life-span development (13 $3^{\text {th }}$ ed.). New York, NY: McGraw-Hill.

Shields, M. \& Wilkins, K. (2013). Smoking, smoking cessation and health disease risk: A 16-year follow-up study. Health Reports, 24(2), 12-22.

Thakur, R., Banerjee, A., \& Nikumb, V. (2013). Health problems among the elderly: a cross-sectional study. Annals of Medical and Health Sciences Research, 3(1), 19-25.

Thurgood, S. L., McNeill, A., Clark-Carter, D., \& Brose, L. S. (2016). A systematic review of smoking cessation interventions for adults in substance abuse treatment or recovery. Nicotine \& Tobacco Research, 993-1001.

Tian, X., Tang, Z., Jiang, J., Fang, X., Wu, X., Han, W., . . Sun, F. (2011). Effects of smoking and smoking cessation on life expectancy in an elderly population in Beijing, China, 1992-2000: An 8-year follow-up study. Journal of Epidemiology, $21(5), 376-384$.

Weil, A. (2011). Spontaneous happiness. London: Hodder \& Stoughton. 